Fontan procedure. Therefore, the sequence of events is consistent with the hypothesis that the increase in PA pressure may have been caused by obstructive tonsillar hypertrophy and was thereby reversed after tonsillectomy in this patient.

Tonsillar hypertrophy is a common cause of OSA in children. Moderate-to-severe OSA is frequently associated with mild pulmonary hypertension, ${ }^{3}$ which is characterized by mild pulmonary vascular remodeling and endothelial dysfunction, as shown in human and animal studies. ${ }^{4,5}$ Therefore, it is possible that the magnitude of structural and functional alterations in pulmonary vasculature induced by nocturnal desaturation had significant impacts on the Glenn circulation, and that these changes were reversed after tonsillectomy in this case. Furthermore, it is interesting to speculate that such derangement in pulmonary circulation caused by OSA might have similar effects on hemodynamics in patients even after the Fontan procedure. This unique case implies that alleviation of OSA (ie, tonsillectomy) may be an efficacious treatment option for high-risk candidates for the Fontan procedure with high PA pressure after the Glenn procedure.

\section{References}

1. Bartmus DA, Driscoll DJ, Offord KP, Humes RA, Mair DD, Schaff HV et al. The modified Fontan operation in children less than 4 years old. J Am Coll Cardiol. 1990;15:429-35.

2. McElhinney DB, Reddy VM, Hanley FL, Moore P. Systemic venous collateral channels causing desaturation after bidirectional cavopulmonary anastomosis: evaluation and management. J Am Coll Cardiol. 1997;30:817-24.

3. Kessler R, Chaouat A, Weitzenblum E, Oswald M, Ehrhart M, Apprill $\mathrm{M}$, et al. Pulmonary hypertension in the obstructive sleep apnoea syndrome: prevalence, causes and therapeutic consequences. Eur Respir J. 1996;9:787-94. Review.

4. Sajkov D, Wang T, Saunders NA, Bune AJ, Mcevoy RD. Continuous positive airway pressure treatment improves pulmonary hemodynamics in patients with obstructive sleep apnea. Am J Respir Crit Care Med. 2002;165:152-8.

5. Thomas BJ, Wanstall JC. Alterations in pulmonary vascular function in rats exposed to intermittent hypoxia. Eur J Pharmacol. 2003;477:153-61.

\title{
Postconditioning in cardiac surgery for tetralogy of Fallot
}

Wanjun Luo, MD, Bei Li, MD, Guoqiang Lin, MD, and Rimao Huang, MD, Changsha, Hunan, P.R. China

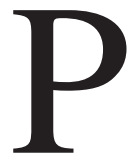

ostconditioning (POC) performed in brief episodes just at the time of ischemic reperfusion can reduce myocardial injury. ${ }^{1,2}$ However, the efficacy of POC in cardiac surgery remains to be determined. We investigated the effect of POC on myocardial protection in children undergoing cardiac surgery for tetralogy of Fallot (TOF).

\section{Patients and Methods}

The hospital ethics committee approved this study, and written informed consent was obtained from all patients' parents. Twentyfour patients aged 1 to 17 years old with TOF were randomized into a POC group $(\mathrm{n}=12$, female/male ratio: $5 / 7)$ and a control group $(\mathrm{n}=12$, female/male ratio: $4 / 8)$. The TOF with pulmonary atresia and absent pulmonary valve were exclusive. Anesthesia was similar in both groups. The operations were performed by the same surgeon (Dr Luo), using hypothermic cardiopulmonary by-

From the Department of Cardiothoracic Surgery, Xiang Ya Hospital, Central South University, Changsha, Hunan, P.R. China.

Received for publication Jan 7, 2007; accepted for publication Jan 17, 2007.

Address for reprints: Luo Wanjun, MD, Department of Cardiothoracic Surgery, Xiang Ya Hospital, Changsha, Hunan, 410008, P.R. China (E-mail: luowanjun@yahoo.com).

J Thorac Cardiovasc Surg 2007;133:1373-4

$0022-5223 / \$ 32.00$

Copyright $\odot 2007$ by The American Association for Thoracic Surgery doi:10.1016/j.jtcvs.2007.01.028 pass $\left(28^{\circ} \mathrm{C}-30^{\circ} \mathrm{C}\right)$ with a hollow-fiber oxygenator and aprotinin $(5 \times$ $10^{5} \mathrm{U} / \mathrm{kg}$ ) administered to the priming volume. The myocardium was protected using intermittent antegrade perfusion of cold blood cardioplegic solution (St Thomas Hospital) in a ratio of 1:4.

POC was started 30

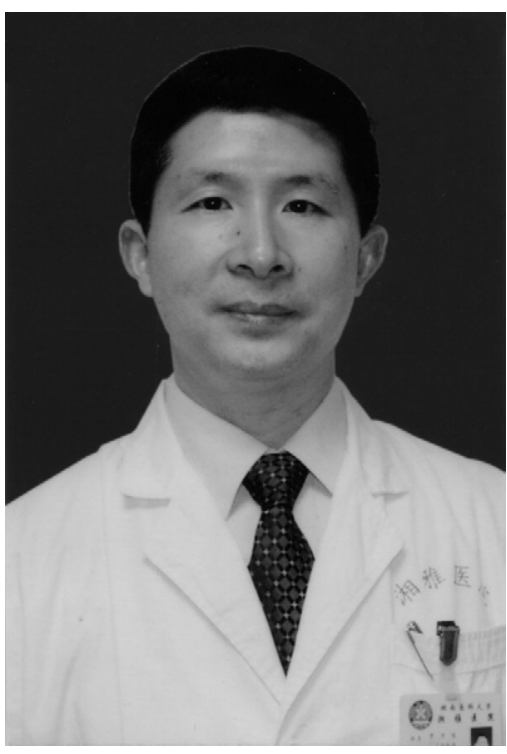

Dr Luo seconds after aortic cross declamping, and the aorta was reclamped for 30 seconds, inducing ischemia; meanwhile, aortic root suction was established during aortic reclamping, and thereafter, the aortic clamp was released for 30 seconds for myocardial reperfusion. This cycle was repeated two times. In the control group, the patients received no aortic reclamping. Blood samples were obtained preoperatively (T1) and 4 (T2), 20 (T3), and 48 (T4) hours after aortic declamping for determination of creatine kinase $\mathrm{MB}$ (CK-MB) and troponin I. All patients were followed for at least 30 days after operation.

The values are expressed as a means \pm standard deviations. The repeated-measures analysis of variance was used to evaluate differences for CK-MB and cardiac troponin I (cTnI) between groups. 


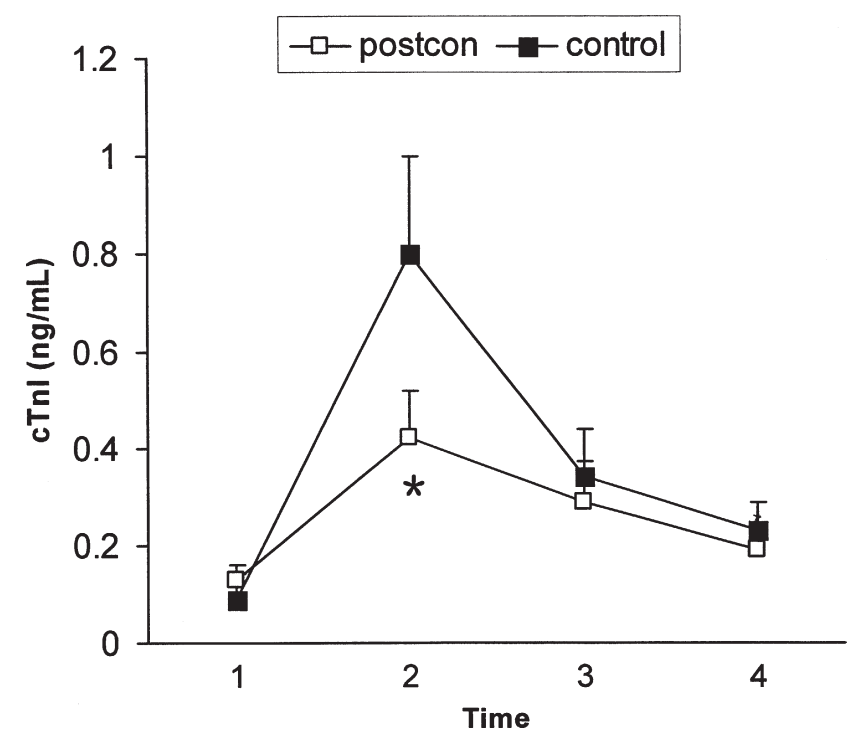

Figure 1. Effect of POC on cTnl. A significant decrease in cTnl levels 4 hours (T2) after reperfusion in the POC group compared with control group. POC, Postconditioning. ${ }^{*} P=.05$.

\section{Results}

There was no mortality or major complications in either group. Patients in both groups were similar in age $(6.1 \pm 5.2$ years and 5.1 \pm 5.6 years, $P=.54)$, weight $(16 \pm 6 \mathrm{~kg}$ and $17 \pm 8 \mathrm{~kg}, P=.52)$, bypass time (96 \pm 23 minutes vs $90 \pm 11$ minutes, $P=.32$ ), aortic claming time $(65 \pm 17$ minutes vs $66 \pm 10$ minutes, $P=.82$ ), duration on ventilator, and stay in the intensive care unit. The inotrope levels during the first 24 hours postoperatively in the POC group were significantly less than were those in the controls $(3.5 \pm$ $1.7 \mu \mathrm{g} \cdot \mathrm{min}^{-1} \cdot \mathrm{kg}^{-1}$ vs $\left.6.0 \pm 2.9 \mu \mathrm{g} \cdot \mathrm{min}^{-1} \cdot \mathrm{kg}^{-1}, P=.017\right)$. The plasma cTnI levels were significantly lower in the POC group than were those in controls at 4 hours after aortic declamping (Figure 1, $P=.05)$. A significant postoperative decrease in CK-MB activity was also observed in the POC group at 4 hours after aortic declamping compared with controls (Figure 2, $P=.034$ ).

\section{Discussion}

The major finding of this study is that POC reduced postoperative peak release by $34 \%$ for CK-MB and $50 \%$ for cTnI, respectively, suggesting that $\mathrm{POC}$ reduced myocardial injury. Our results further provide evidence that POC could also be initiated in the setting of cardiac surgery with cardioplegia as effective as that without cardioplegia in percutaneous coronary intervention. ${ }^{2}$ To our knowledge, the present study is the first controlled, randomized clinical trial evaluating the effect of POC on myocardial protection in cardiac surgery. Staat and colleagues ${ }^{2}$ reported the effects of POC on patients undergoing percutaneous coronary intervention for acute myocardial infarction. These encouraging results were also attractive to cardiac surgeons, because the cardioplegic-arrested heart is one of the few controlled clinical models of myocardial ischemia, in which POC as a simple procedure could be applicable at the early time of reperfusion by using intermittent aortic crossclamping. ${ }^{3}$

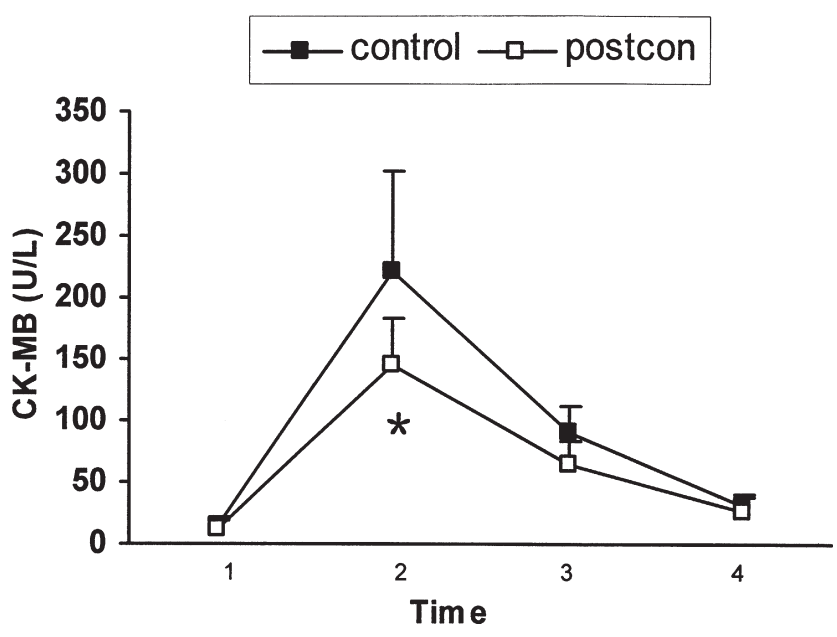

Figure 2. Effect of POC on CK-MB. A significant decrease in CK-MB levels 4 hours (T2) after reperfusion in the POC group compared with control group. POC, Postconditioning; CK-MB, creatine kinase MB. ${ }^{*} \boldsymbol{P}=.034$.

Another finding of this study is that two cycles of intermittent brief episodes of ischemia induced by repeat aortic clamp was effective in children undergoing TOF repair. This result is in contrast to the majority of previous reports concerning animals with 3 or more cycles of POC and humans in percutaneous coronary intervention with 4 cycles of POC. ${ }^{1-3}$ Galagudza and colleagues ${ }^{4}$ reported that a single 2-minute cycle of ischemia during reperfusion could convert ventricular fibrillation into regular rhythm in an isolated rat heart. Serviddio and associates ${ }^{5}$ reported brief hypoxia of 3 minutes before normoxic reperfusion (equal to POC) reduced myocardial injury in an isolated rat heart undergoing cold cardioplegic arrest. We speculated that such differences could be due to multiple factors, including factors dependent on pathology, species, or cardioplegia. However, these issues need further investigation.

In conclusion, the present study demonstrated that POC protects cyanotic myocardium undergoing cardioplegic arrest. These data support the need for a larger clinical trial of POC in pediatric cardiac surgery.

\section{References}

1. Zhao ZQ, Corvera JS, Halkos ME, Kerendi F, Wang NP, Guyton RA, et al. Inhibition of myocardial injury by ischemic postconditioning during reperfusion: comparison with ischemic preconditioning. Am J Physiol Heart Circ Physiol. 2003;285:H579-88.

2. Staat P, Rioufol G, Piot C, Cottin Y, Cung TT, L'Huillier I, et al. Postconditioning the human heart. Circulation. 2005;112:2143-8.

3. Ramzy D, Rao V, Weisel RD. Clinical applicability of preconditioning and postconditioning: the cardiothoracic surgeons' view. Cardiovasc Res. 2006;70:174-80.

4. Galagudza M, Kurapeev D, Minasian S, Valen G, Vaage J. Ischemic postconditioning: brief ischemia during reperfusion converts persisten ventricular fibrillation into regular rhythm. Eur J Cardiothorac Surg. 2004:25:1006-10

5. Serviddio G, Venosa ND, Federici A, D’Agostino D, Rollo T, Prigigallo F, et al. Brief hypoxia before normoxic reperfusion (postconditioning) protects the heart against ischemia-reperfusion injury by preventing mitochondria peroxide production and glutathione depletion. FASEB J. 2005;19:345-61. 